\title{
A CRIATIVIDADE NO ÂMBITO DA ECOFORMAÇÃO: UMA PERSPECTIVA A PARTIR DA COMPLEXIDADE E DA TRANSDISCIPLINARIDADE
}

\author{
Berenice Feitosa da Costa Aires ${ }^{1}$ \\ João Henrique Suanno ${ }^{2}$
}

\begin{abstract}
Resumo: Muitas práticas e metodologias educacionais acabam se concentrando e se limitando ao desenvolvimento de conteúdos sem relacioná-los à diversidade de conhecimentos e vivências que é o educando em sua individualidade e sociabilidade. Esse trabalho tem como objetivo apresentar algumas reflexôes que revelem as possibilidades para unir escola e o ambiente no qual ela está inserida, em que o aluno seja globalmente visto e possa desenvolver aquilo que lhe faz capaz de transformar seu ambiente e as suas relaçóes: a criatividade. Para Tanto utilizamos de um levantamento bibliográfico a partir dos conceitos como o de complexidade, transdisciplinaridade e ecoformação, de Edgar Morin (2005, 2007, 2010), Torre (2005, 2008 2010), Suanno $(2013,2014)$ que são fundamentais para desconstruir paradigmas que assolam a educação, mostrando que, a partir desta, inovaçôes que priorizem a sustentabilidade, o meio ambiente e promovam mudanças sociais são imprescindíveis para a atualidade e ressignificação das práticas educacionais.
\end{abstract}

Palavras-chave: Educação Ambiental. Criatividade. Complexidade. Transdisciplinaridade. Ecoformação.

1 Doutora em Ciências Ambientais pela Universidade Federal de Goiás - UFG. Mestre em Administração da Educação pela Universidade de Brasília - UnB. Professora adjunta da Universidade Federal do Tocantins - UFT; Aluna de Estágio Pós-doutoral do Programa de Pós-Graduação Interdisciplinar em Educação, Linguagem e Tecnologias - IELT/UEG, sob a orientação do Prof. Dr. João Henrique Suanno.

2 Pós-Doutor em Educação pela Universidade de Barcelona - UB/ES. Doutor em Educação pela Universidade Católica de Brasília - UCB/DF. Mestre Educação pela Universidad de La Habana/ Cuba revalidado pela Pontifícia Universidade Católica de Goiás - PUC/GO. Professor titular da Universidade Estadual de Goiás. Professor do Programa de Pós-Graduação Interdisciplinar em Educação, Linguagem e Tecnologias - MIELT/UEG. 


\title{
CREATIVITY IN ECOFORMATION: A PERSPECTIVE FROM COMPLEXITY AND TRANSDISCIPLINARITY
}

\begin{abstract}
Many educational practices and methodologies end up concentrating and limiting themselves to the development of contents without relating them to the diversity of knowledge and experiences that is the educating in their individuality and sociability. This work aims to present some reflections that reveal the possibilities to unite school and the environment in which it is inserted, in which the student is globally seen and can develop what makes him able to transform his environment and his relationships: creativity. For So much we use a bibliographical survey based on the concepts such as complexity, transdisciplinarity and ecoformation, by Edgar Morin (2005, 2007, 2010), Torre $(2005,2008$ 2010), Suanno $(2013,2014)$, which are fundamental to deconstruct paradigms that devastate education, showing that, from this, innovations that prioritize sustainability, the environment and promote social changes are essential for the actuality and resignification of educational practices.
\end{abstract}

Keywords: Environmental Education. Creativity. Complexity. Transdisciplinary. Eco-formation.

\section{INTRODUÇÃO}

O modelo de ensino vivenciado tradicionalmente pelas escolas promove uma educação para a qual o indivíduo é único e exemplo de uma riqueza de sentimentos e capacidades? A princípio, a escola enfrentam uma dificuldade em oferecer uma formação que abarque a amplitude que é o ser humano quando o consideramos como reflexivo e criativo, assim, acaba-se por fechar os olhos para a dimensão transformadora no/do âmbito escolar e mergulhando em conteúdos meramente transmitidos e restritos, por vezes sem nenhuma associação com ambiente em que vivem.

Sentimentos, pensamentos e expressões da individualidade são tolhidos e ignorados na escola, assim como os conhecimentos são isolados e divididos como se não pudessem possuir relações entre eles e isso, no ambiente educacional, se apresenta numa desvalorização do humano e num planejamento pedagógico que se foca em disciplinas afastadas entre si e da dimensão integral do sujeito. Logo, é preciso repensar toda a formação que envolve educação, desde a formação de docentes até a oferecida aos alunos, dentro de uma perspectiva mais ampla e coerente com a sociedade e aquilo que esta espera dos seus cidadãos.

Sendo assim, o espaço escolar e suas metodologias devem ser revistos e trazidos para reflexões que possam ser a base de mudanças e transformações, as quais podem ultrapassar os limites da escola, pois implicam diretamente em diversos âmbitos. Desse modo, analisar, compreender e refletir são ações fundamentais para uma escola engajada numa transformação educacional e social, mas tais ações envolvem comprometimento e disposição de todos aqueles que, direta ou indiretamente, participam de alguma face da educação, seja ela escolar, familiar, profissional, entre outras. 
Se a criatividade que poderia tornar o frequentador da escola um cidadão ativo, reflexivo, questionador e problematizador é simplesmente deixada de lado em prol de uma educação controladora e inibidora de uma amplitude de conhecimentos, projetos que incentivassem a criatividade, percebessem o educando numa amplitude de dimensões sociais e práticas e associassem os conteúdos entre eles e entre a realidade de maneira a oferecer uma formação integral, trariam contribuições inefáveis para a sociedade em todas as suas faces, inclusive aquela da sustentabilidade e do meio ambiente. Desse modo, é na existência de uma complexidade, tal como Morin (2007) a concebe, e na possibilidade de uma transdisciplinaridade que deveríamos nos ater numa busca por mudanças.

\section{Um diagnóstico da realidade educacional: a complexidade que permeia as relaçóes}

Um olhar atento para o currículo e para as metodologias envolve repensar, constantemente, a didática e os objetivos que cercam o ensino. É necessário perceber as tendências das práticas pedagógicas e refletir sobre o que se espera da formação que está se construindo, analisando sua diversidade e especificidades dentro de uma visão ampla da realidade. É preciso, então, que as disciplinas não sejam reduzidas a fragmentos de conhecimento para pensá-las numa complexidade de fenômenos, algo que Morin (2006) propõe como uma reforma do pensamento na qual este não se fecha em conteúdos, mas se tece e se amplia em uma rede de conhecimentos em comunicação uns com os outros.

O desafio da complexidade permeia não somente a esfera escolar, pois tudo se relaciona e a parte não pode ser destacada do todo sem perder algo de sua significação. Obviamente, separar algo do todo permite conhecê-lo em seus pormenores, no entanto, faz necessário restituí-lo ao seu lugar para que seja concebido integralmente e tenha a sua importância e relevância para com aquilo que o circunda. Isolar conhecimentos tem a sua face benéfica, isso a ciência comprova em seus experimentos cada vez mais minuciosos, mas que só fazem sentido quando os inserimos dentro de um contexto. O mesmo ocorre, ainda que numa perspectiva diversa, com a metodologia e a prática de ensino: ao estudar as partes não se compreende o integral, pois isso só se faz por um esforço em entrelaçar conhecimentos para que sejam significantes dentro de uma realidade.

Doravante, se as disciplinas se organizam em conteúdos, é um grande equívoco concebê-los como pedaços soltos e, por vezes, sem ligação com a vivência do aluno. Repensar, ressignificar e articular meios para que o conhecimento seja tomado em sua amplitude é o caminho para que o papel da escola de formar indivíduos ativos e conscientes se concretize, trazendo, assim, um movimento àquilo antes estático em concepções fragmentadas. Nas palavras de Morin,

Deveríamos, portanto, ser animados por um princípio de pensamento que nos permitisse ligar as coisas que nos parecem separadas umas em relação às outras. Ora, o nosso sistema educativo privilegia a separação em vez de praticar a ligação. A organização do conhecimento sob a forma de disciplinas 
seria útil se estas não estivessem fechadas em si mesmas, compartimentadas umas em relação às outras; assim, o conhecimento de um conjunto global,o homem, é um conhecimento parcelado. (2003, p. 14)

Alcançar o sentido de um pensamento é interligá-lo a outros, é reconhecer que ele se desenvolve diante de uma enorme gama de relações e, se buscamos compreendê-lo, serão estas relações que observaremos, pois "O princípio de separação torna-nos talvez mais lúcidos sobre uma pequena parte separada do seu contexto, mas nos torna cegos ou míopes sobre a relação entre a parte e o seu contexto" (MORIN, 2003, p. 14). Assim, se os conteúdos programáticos se restringem a si próprios, o aspecto racional do aluno é colocado acima das demais qualidades que o constituem.

É preciso pensar a prática e o planejamento educacional através de uma ressignificação da atuação e do pensamento da instituição, sendo a complexidade que chegamos quando abrimos os horizontes do processo educativo, uma complexidade que desperta e estimula um novo olhar sobre a realidade e o ambiente que nos circunda, já que abre o caminho para uma compreensão dos questionamentos acerca do humano.

O caminho para um pensamento complexo não é simples. Envolvendo mudanças de diversas ordens, esse caminho torna-se uma empreitada que carece derrubar comportamentos e condições para, então, reconstruir uma nova realidade. A quebra de paradigmas, ou seja, dos "princípios que organizam o conhecimento de uma forma sobre a qual estamos inconscientes" (MORIN, 2005, online) é um dos percalços que se apresentam para o pensamento complexo, pois chegarmos a este é se desvencilhar de uma simplificação que o mutila e o impede de inovar.

O rompimento de ações ou, em maior escala, de paradigmas envolve, primeiramente, a identificação do problema para, a partir dele, vislumbrar possíveis transformações. É preciso ter ímpeto de mudança e iniciativa, assim como considerar as dimensões contextuais, pessoais, constitutivas e avaliativas. Sendo assim, aqueles que almejam uma educação pautada no respeito a individualidade e as especificidades de cada se veem numa exigência de atitude que engloba engajamento, resiliência e persistência.

Considerar a complexidade se torna fundamental para uma nova estruturação do ensino, metodologias e currículos, mas para iniciar e desenvolver um processo que venha a culminar em mudanças, não basta apenas direcionar o olhar para a complexidade no espaço educacional, mas para aquela que na qual o sujeito se constrói e se evidencia: cabe pensar a complexidade dos conteúdos para o indivíduo que é, em si, uma complexidade, que levará a formação que teve para suas relações e ações na cultura familiar, e em tantos outros meios que o envolvem.

\section{A transdisciplinaridade como abertura à criatividade}

Se lidamos com indivíduos em sua complexidade, as disciplinas que priorizam e se limitam aos conteúdos já não correspondem mais às expectativas. 
Uma transdisciplinaridade emerge da complexidade quando a escola pretende uma metodologia que instigue e forneça para o aluno instrumentos para que ele articule seus conhecimentos com a sua vivência, seja ela dentro ou fora do ambiente educacional.

Por toda parte, se reconhece a necessidade de interdisciplinaridade, esperando
o reconhecimento da relevância da transdisciplinaridade, seja para o estudo da
saúde, da velhice, da juventude, das cidades... mas a transdisciplinaridade só
é uma solução no caso de uma reforma do pensamento. É preciso substituir
um pensamento que separa por um pensamento que une, e essa ligação
exige a substituição da causalidade uni linear e unidimensional por uma
causalidade em círculo e multirreferencial, assim como a troca da rigidez da
lógica clássica por uma dialógica capaz de conceber noções ao mesmo tempo
complementares e antagônicas; que o conhecimento da integração das partes
num todo seja completada pelo reconhecimento da integração do todo no
interior das partes. (MORIN, 2003, p. 34)

Desde que utilizado por Jean Piaget em 1970, durante um Seminário Internacional realizado na Universidade de Nice, na França, o termo transdisciplinar ganha espaço nas discussões e reflexões sobre o currículo e sua prática. Em 1994, em Convento da Arrábida, os pensadores Lima de Freitas, Edgar Morin e Basarab Nicolescu redigiram a Carta da transdisciplinaridade, o que é um marco para a compreensão do humano, numa visão global, e para a educação, na medida em que se mostra uma reflexão acerca do conhecimento e do relacionamento que temos com este.

É importante ressaltar que conceber a transdisciplinaridade como um método a ser seguido não é condizente com o seu fundamento e mesmo desmontaria suas bases, pois, todavia, ao limitar e estagnar seus preceitos em um modelo, a noção de transdisciplinaridade não remeteria mais a uma ação que se flexibiliza diante do humano para respeitá-lo em sua complexidade e diversidade.

Quando relativa aos conteúdos, a transdisciplinaridade, como o próprio termo sugere, se apresenta como algo que "está ao mesmo tempo entre as disciplinas, através das diferentes disciplinas e além de toda disciplina" (NICOLESCU, 1997, p.1). Logo, essa concepção muito se afasta da abordagem comumente realizada, mostrando que a transdisciplinaridade "não procura o domínio de várias disciplinas, mas a abertura de todas as disciplinas ao que as une e as ultrapassa" (FREITAS; MORIN; NICOLESCU, 1994, online) onde "Toda e qualquer tentativa de reduzir o ser humano a uma definição e de dissolvê-lo em estruturas formais, sejam quais forem, é incompatível com a visão transdisciplinar" (FREITAS; MORIN; NICOLESCU, 1994, online).

Sendo a transdisciplinaridade um convite à reflexão acerca do humano e como este se relaciona com o mundo, repensar a educação enquanto uma dessas relações está no âmago de uma concepção de conhecimento para a qual a criatividade é essencial, pois se procuramos uma atmosfera educacional que contextualize e integralize seus conteúdos, a "educação transdisciplinar reavalia o papel da intuição, do imaginário, da sensibilidade e do corpo na transmissão do 
conhecimento" (FREITAS; MORIN; NICOLESCU, 1994, online), promovendo, assim, um espaço para que o criativo aflore.

A transdisciplinaridade não pode abdicar da criatividade. Se a complexidade é a união entre a unidade e a multiplicidade, entre o homem e aquilo que o rodeia, inclusive em termos abstratos, a criatividade emerge de uma pluralidade diversa de indivíduos como algo que vem a desconstruir os limites conteudistas das disciplinas. Instigar a criatividade é respeitar o sujeito em suas capacidades e ações que o fazem único e, também, um "tecelão" de sua vivência exposta de forma espontânea e desvinculada de ambições restritivas.

Se a complexidade atenta para uma diversidade em diversos planos e, em última instância, no todo que é a realidade, temos um campo profícuo onde a criatividade se aguça. No entanto, nessa diversidade que nos é comum, seja enquanto seres biológicos ou sociais, que surgem as mais variadas situações que podem ser concebidas de maneira totalmente negativa e encerrada em si, ou como estopim para inovações e transformações.

\section{A criatividade aflorando das adversidades}

As noções de complexidade e transdisciplinaridade trazem a tona um questionamento acerca da criatividade, por numerosas vezes, ignorada e reprimida. Mas se tecer considerações teóricas acerca da criatividade pode, a primeira vista, se assemelhar a algo simples, é importante enfatizar que ela é tão laboriosa quanto a sua prática. Compreender e refletir sobre o que norteia e torna efetiva a criatividade envolve transitar por diversos conceitos e perspectivas que se manifestam a partir da diversidade e das adversidades próprias ao desenvolvimento e às relações humanas.

A criatividade, então, pode surgir numa circunstância onde tudo parecia desfavorável: ressignificar o erro é lidar com as adversidades, fazendo daquele uma "oportunidade para pensar outra possibilidade e se motivar na continuidade da busca" (SUANNO; TORRE; H. SUANNO, 2014, p. 18), e destas uma superação e reconstrução de si e do ambiente, trazem, para a educação, um ganho inestimável, pois as metodologias e práticas podem reestruturadas e desenvolvidas numa perspectiva inovadora.

Para Suanno, "As adversidades, se percebidas como oportunidades de crescimento, podem ser de um novo ciclo e carregar forças de renovação, criação e inovação" (SUANNO, 2013, p. 31), destacando, ainda, que "em situações de grandes conflitos, caso a postura do sujeito, ou instituição, seja de enfrentamento e criatividade, o que é elaborado, quase sempre, é inovador." (SUANNO, 2013, p. $31)$.

Enquanto instrumentos de criação, as adversidades, que emergem da diversidade, ganham uma dimensão positiva e profícua no âmbito escolar. Logo, a formação docente deve se preparar para defrontar situações múltiplas e fazer destas um salto para transformações. Para Torre (2010), 
A adversidade criadora e a diversidade são pilares que deveriam caminhar juntos quando falamos em formação docente. Juntos porque tem que trabalhar a prática com realidades múltiplas, na cultura, no social e no econômico, no lingüístico, nos modos de aprender e até nas personalidades dos alunos. Sendo assim, é sem sentido continuar difundindo modelos que não se partam destas premissas. A diversidade deveria ser, para diretores e professores, sinônimo de riqueza e fonte de criatividade. A adversidade é uma quebra de algo com o qual tínhamos um forte vínculo ou com uma realidade construída (doença, morte, separação, perda, fracassos da vida ...). Abala os alicerces do sentido da vida. Quando nós sabemos ajustá-la e reconstruímos uma nova realidade estamos sendo fortes, resilientes. Se esta situação leva-nos mais adiante e conseguimos realizar contribuições inovadoras, entramos na criatividade paradoxal ou adversidade criadora. E é esta que intencionamos promover diante de situações infelizes. Reconstruir a casa destruída pela adversidade. (TORRE, 2010, p.13)

A adversidade criadora, além das especificidades apontadas acima, é um incentivo para a construção de uma postura resiliente. Se é no enfrentamento das dificuldades que o indivíduo põe sua criatividade à prova, essa situação contribui para que, cada vez mais, ultrapassar os obstáculos se torne leve, não porque a objeção seja menor, mas porque, sendo desenvolvida, a resiliência supera e ressignifica o problema, estando no cerne da renovação e transformação. Desse modo "A resiliência é uma capacidade criadora, uma atitude, com característica superadora, de enfrentamento das dificuldades. $\mathrm{O}$ indivíduo com esse talento desenvolve uma capacidade de enfrentamento à todas das situações que se the apresenta." (SUANNO, 2013, p. 40)

Se "o diferencial entre os sujeitos está na forma como estes encaram as situações de sofrimento e como as transformam em aprendizagens, em pensamento criativo" (SUANNO, p. 33), espera-se do docente uma atitude proativa, crítica e, se possível, resiliente perante os sofrimentos que possam lhe acompanhar no exercício da profissão. São esses docentes que a Rede Internacional de Escolas Criativas busca conhecer e sobre os quais procura refletir e colher experiências que sirvam como exemplo as instituições.

\section{A Rede internacional de Escolas Criativas: um estímulo à transformaçáo}

É a um incentivo e a uma investigação do meio educacional que não se reduz à sala de aula que a Rede internacional de Escolas Criativas vem a contribuir para "o reconhecimento e a socialização de projetos e processos institucionais, construídos coletivamente, e que sejam criativos, transformadores, fruto de uma nova consciência e que seja nutrida por uma cultura de mudança (...) (SUANNO; TORRE; SUANNO, 2014, p.21). Desse modo, para a RIEC, é a uma escola criativa que devemos nos encaminhar quando priorizamos uma educação que emancipe, que transforme e que perceba o educando em suas especificidades, instigando-o a ser consciente e reflexivo em suas ações. 
Rompendo com uma lógica do conhecimento naturalizada, as escolas criativas vem a questionar todo um aparato curricular restrito aos conteúdos programáticos, voltando-se ao indivíduo e incentivando uma formação docente que saia dos moldes tradicionais, recriando metodologias e conceitos que se concentrem em valores humanos e no desenvolvimento consciente em relação ao meio ambiente e suas particularidades.

Segundo Torre (2014), a escola criativa terá como "pontos cardiais" transcender, recriar, valorizar e transformar a realidade educacional, mais precisamente, primar pela criatividade é transcender as práticas educacionais que não concebem o indivíduo como ser transformador, é recriar, a partir dessa transcendência, novos meios e estruturas que propiciem uma nova metodologia, é valorizar os potenciais de todos os envolvidos no processo educativo, sempre observando que o erro é tido como oportunidade de mudança e, finalmente, transformar, através de outras perspectivas, a relação com o conhecimento das instituições escolares e da vida como um todo.

É importantíssimo ressaltar que a RIEC não é estruturada visando fornecer um modelo de escola a ser seguido, mas sim voltada a pesquisa e contribuições ao âmbito escolar, logo, ela considera as escolas como únicas dentro de suas especificidades e nelas analisa e reflete sobre os projetos que podem vir a se tornarem inspirações e referências para outras instituições, prezando, sempre, o viés criativo, transdisciplinar e imaginativo.

As escolas criativas atuam, desse modo, como incentivadoras de transformações pelo próprio exemplo, pois ao mostrarem novas e profícuas possibilidades de ensino, despertam o interesse e estimulam instituições a adotarem outros caminhos. Por conseguinte, a RIEC tem uma preocupação em levar seus conhecimentos a todos que procuram se empenhar numa educação crítica e libertadora, para isso, elabora e desenvolve pesquisas, incentiva publicações que difundam conhecimentos, aprofunda e instiga debates e reflexões, almejando, assim,

\footnotetext{
Uma escola baseada em processos de aprendizagem a partir de vivência de práticas democráticas, dialógicas e de fruição estética. Pautada em valores humanos, solidariedade, responsabilidade social, responsabilidade ambiental, autonomia, igualdade, justiça social, direitos humanos, liberdade de expressão, democracia, ética, convivência harmoniosa, que favoreçam o desenvolvimento de uma consciência interior." (SUANNO; TORRE; SUANNO; 2014, p.27)
}

A partir de um ensino que considera a complexidade, a transdisciplinaridade e a criatividade, e para o qual a RIEC se volta, é possível ao aluno caminhar pelos diversos conhecimentos e relacioná-los a sua vivência enquanto ser humano global, mas esse caminho só se realiza se existirem condições de desenvolvimento e uma esfera propícia para sustentar toda a diversidade que somos e em que estamos. São essas condições que estão cada vez mais sendo ignoradas num desrespeito à natureza e ao meio-ambiente. 
Uma escola criativa não pode, então, se abster de pensar o ambiente que a circunda, pois a criatividade precisa dele para se desenvolver ao mesmo tempo que ela se constituirá como importante instrumento para promover transformações que o preservem. Uma ecoformação é indispensável diante da atual configuração mundial e, tendo a escola "um papel fundamental na formação de cidadãos criativos, resilientes e empreendedores, que possam identificar problemas da realidade e solucioná-los" (PUKALL, ANDRADE, SILVA, 2015, p. 186) nada mais coerente que a questão ambiental seja levada à sala de aula.

\section{Criatividade e ecoformação: um vínculo fundamental}

Pensar o ensino em sua complexidade e numa transdisciplinaridade que remetem à criação, é concebê-lo em sua relação como o todo. Desse modo, enquanto algo tão fundamental ao ser humano, a natureza não pode deixar de ser objeto de reflexão acerca de suas implicações diretas sobre a sociedade.

Diante da situação preocupante do meio ambiente, uma postura criativa abriria horizontes para a preservação e conservação daquilo que dependemos para sobreviver. A sustentabilidade encontraria terreno fértil para se concretizar num âmbito em que sua importância fosse evidenciada em suas diversas faces e relações, chamando a atenção para o fato de que ela não se limita ao aspecto ecológico, mas de desenrola sobre a ciência, cultura, economia, entre outros.

A ecoformação, por conseguinte, se direciona a um pensamento e a uma ação efetiva e consciente sobre o meio ambiente, que não visa a obtenção desvairada de recursos, mas um consumo consciente que preze pelo bem estar geral. Sendo a escola criativa baseada em valores humanos, dentre os quais a solidariedade e a responsabilidade ambiental, o processo ecoformador não beneficia somente o meio ambiente, mas a própria sociedade, pois colabora com o desenvolvimento de um cidadão crítico, responsável e engajado em suas ações, já que "Ecoformar é educar para um desenvolvimento sustentável e solidário uma educação da solidariedade, do comprometido com o planeta e com todos seus habitantes, o que inclui educação ambiental, educação para os direitos humanos e para a paz" (SUANNO; TORRE; SUANNO, 2014, p. 28)

A ecoformação tem na escola uma importante aliada, já que é nela que se pode conhecer os princípios da relação com o ambiente baseada no respeito, na preservação e no uso consciente do mesmo, promovendo assim a "responsabilidade, a autonomia, o sentido crítico, a capacidade de tomar decisões, a busca de soluções para os problemas e favorece a criatividade." (SUANNO; TORRE; SUANNO, 2014, p. 28). Os projetos relativos à ecoformação servem de referência para uma abordagem integral do indivíduo e evidenciam a liberdade de expressão, criação e reflexão, o que é plenamente condizente com a complexidade e transdisciplinaridade que permeiam a realidade escolar.

A transformação da prática educativa em convergência com as necessidades de sustentabilidade planetária e o estímulo a relações de convivência solidária e criativa são aspectos fundamentais em projetos de instituições educativas 
preocupadas em qualificar a vida no planeta. A sociedade vem sofrendo mudanças em muitos aspectos, entre eles a transformação da sociedade industrial para a sociedade da informação. Isto traz um progresso que exige saber lidar com o imprevisível e estar em busca contínua de novas soluções, o que exige enfrentar os problemas de forma inovadora e criativa. (TORRE; SILVA, 2015, p.17)

Sendo assim, a ecoformação é uma contribuição mútua entre meio ambiente e a educação: a reciprocidade entre ambos culmina na efetivação de um ensino humanizado ao mesmo tempo que ampara o desenvolvimento de ações ecológicas tão necessárias na atualidade. Em outras palavras, "a escola tem um importante papel na ação formativa do sujeito e da sociedade em relação à sua interação com a natureza e os meios de realizar uma convivência sadia e duradoura, que perpetue o bem estar pessoal e social com o ambiente." (SUANNO; TORRE; SUANNO, 2014, p. 27).

\section{CONSIDERAÇÓES FINAIS}

Toda esta reflexão aqui traçada do estudo, que se encontraram com o intuito de formar uma nova roupagem para a contemporaneidade e propiciar discussões e atitudes de mudanças em cenários educativos que buscam por transformações para desenvolver a formação integral do sujeito e se voltar ao bem tanto individual quanto social e planetário. As bases epistemológicas da complexidade, transdisciplinaridade e ecoformação, as quais propiciaram verificar que a criatividade no contexto educativo parte do pressuposto de uma educação formadora e transformadora, com finalidades que visam partir da vida e se voltar para a vida, valorizando o ser humano como um ser completo em seu interior e integrante do planeta.

Esta concepção de educação criativa busca, por meio das mudanças, a interligação do conhecimento como princípio transdisciplinar que valoriza o ser humano como um todo. Uma educação com o predomínio das ações planejadas e executadas coletivamente, apreciando o potencial criativo tanto discente e docente, quanto da instituição e de toda a comunidade educativa.

\section{REFERÊNCIAS}

FREITAS, L., MORIN, E., NICOLESCU, B. (1994). Carta da Transdisciplinaridade. Disponível em: www.redebrasileiradetransdisciplinaridade.net. Acesso em 10 de outubro de 2016.

GUimarãeS, M. (2004). A formação de educadores ambientais. São Paulo: Papirus.

LEFF, E. (2001). Saber ambiental: sustentabilidade, racionalidade, complexidade, poder. Trad. Lucia Mathilde Endlich Orth. $3^{\mathrm{a}}$ ed. Petrópolis: Vozes.

LOUREIRO, C. (2004). Trajetória e Fundamentos da educação ambiental. São Paulo: Cortez. 
LUDKE, M., \& ANDRE, M. E. D. A. (1986). Pesquisa em educação: abordagens qualitativas. São Paulo: EPU.

MORAES, M. C., \& VALENTE, J. A. (2008). Como pesquisar em educação a partir da complexidade e da transdisciplinaridade? São Paulo: Paulus.

MORIN, E. (2003). Da necessidade de um pensamento complexo. In SILVA, J. M (Org.). Para navegar no século XXI: tecnologias do imaginário e cibercultura. $3^{\mathrm{a}} \mathrm{ed}$. Porto Alegre: Sulinas/Edipucrs.

MORIN, E. (2005). Educação na era planetária. Disponível em www.edgarmorin.sescsp. org.br/textos/educação-na-era-planetária/?page $=2$.

MORIN, Edgar. (2003). A cabeça bem feita: repensar a reforma, reformar o pensamento. $8^{\mathrm{a}}$ ed. Rio de Janeiro: Bertrand Brasil.

MORIN, Edgar. (1996). Ciência com consciência. Rio de Janeiro: Bertrand Brasil.

MORIN, Edgar. (2007). Introdução ao pensamento complexo. Trad. Eliane Lisboa. $3^{\text {a }}$ ed. Porto Alegre: Sulinas.

MORIN, E. (2010). Os sete saberes necessários à educação do futuro. $3^{\mathrm{a}}$. Ed. São Paulo: Cortez.

PINHO, M. J. (2007). Políticas de formação de professores: Intenção e realidade. Goiânia: Cânone.

SUANNO, J. H. (2014). Ecoformação, transdisciplinaridade e criatividade: a escola e a formação do cidadão do século XXI. En: SUANNO J. H., MORAES, M. C. (Org.). O pensar complexo na Educação: sustentabilidade, transdisciplinaridade e criatividade. V. 1, p. 171-182. $1^{\mathrm{a}}$ ed. São Paulo: WAK Editora.

SUANNO, J. H. (2013). O desenvolvimento da criatividade em um ambiente transdisciplinar de aprendizagens. En: SUANNO, J. H., \& SUANNO, M. V. R., SANTOS, A. (Org.). Didática e Formação de Professores: complexidade e Transdisciplinaridade. V. Único, p. 149-166. $1^{\text {a }}$ ed. Porto Alegre: Sulina.

SUANNO, J. H. (2014). Rede Internacional de Escolas Criativas. En: SUANNO, J. H., SUANNO, M. V. R., \& PINHO, M. J. (Org.). Formação de Professores e interdisciplinaridade: diálogo investigativo em construção. V. único, p. 15-32. $1^{\mathrm{a}}$ ed. Goiânia: Editora América.

SUANNO, J. H. (2015). Transdisciplinaridade, Criatividade e Terceiro Incluído na Formação de Professores. En: BEHRENS, M. A., TEODORA, R. (Org.). Complexidade e Transdisciplinaridade: novas perspectivas teóricas e práticas para a formação de professores. V. único, p. 107-122. 1ª ed. Curitiba: Appris. 
SUANNO, J. H., MORAES, M. C. (Org.). (2014). O pensar complexo na Educação: sustentabilidade, transdisciplinaridade e criatividade. $1^{\text {a }}$ ed. São Paulo: WAK Editora.

SUANNO, J. H., \& SUANNO, M. V. R., \& PINHO, M. J. (Org.). (2014). Formação de professores e interdisciplinaridade: diálogo investigativo em construção. $1^{\mathrm{a}} \mathrm{ed}$. Goiânia: América.

SUANNO, J. H., \& SUANNO, M. V. R., SANTOS, A. (Org.). (2013). Didática e Formação de Professores: Complexidade e Transdisciplinaridade. $1^{\mathrm{a}}$ ed. Porto Alegre: Editora Sulina.

SUANNO, J. H., \& SUANNO, M. V. R., \& PINHO, M. J., \& ZWIEREWICZ, M., \& SILVA, V. L. S. E.; \& LIMAVERDE, P. (2015). Escolas, práticas educativas e projetos pedagógicos: pesquisas da Rede Internacional de Escolas Criativas. En: Revista do Programa de Pós-Graduação em Ensino na Educação Básica do CEPAE-UFG. (Org.). V. 26, p. 583-598. $2^{a}$ ed. Goiânia: UFG.

SUANNO, J. H., \& SUANNO, M. V. R; PINHO, M. J. (2015). Escola, Criatividade e Projetos Ecoformadores. En: SILVA, C. C., ROSA, S. V. L. (Org.). ANOS INICIAIS DO ENSINO FUNDAMENTAL: Política, Gestão, Formação de Professores e Ensino. V. 1, p. 175-190. $1^{\text {a }}$ ed. Campinas: Mercado de Letras.

SUANNO, M. V. R., \& DITTRICH, M., MAURA, M. A. P (Org.). (2013). Resiliência, Criatividade e Inovação: potencialidades transdisciplinares na educação. Goiânia: UEG/Ed. América.

TORRE, S.; SILVA, V. L. S. (2015). Ecoformação e Transdisciplinaridade na Rede de Escolar Criativas. Revista Dynamis (p. 15-30). Blumenau, v. 21, n. 1.

TORRE, S. (2010). Adversidad y Diversidad creadoras. En: Torre, S., Pujol, M.A., Rajadle, N., Borja, M. (Org.) Innovación y Creatividad. Barcelona: Giad.

TORRE, S. (2005). Dialogando com a criatividade. São Paulo: Mandras.

TORRE, S. (2008). Ecologia dos saberes: complexidade, transdisciplinaridade e educação. São Paulo: Antakarana/WHH-Willis Harman House.

ZWIEREWICZ, M. (2009). Fortalecer a resiliência na escola por meio de emoções e valores. En: TORRE, S.; ZWIEREWICZ, M. (Orgs.). Uma escola para o século XXI: Escolas criativas e resiliência na educação (p. 43-52). Florianópolis: Insular. 